\title{
A ESCOLARIZAÇÃO DOS TRABALHADORES ADULTOS NO CONTEXTO DE MODERNIZAÇAO DO ESTADO DE MINAS GERAIS (1894-1917)
}

\author{
Vera Lúcia Nogueira ${ }^{1}$ \\ Luciano Mendes de Faria Filho ${ }^{2}$
}

\section{RESUMO}

Neste artigo apresentamos uma reflexão sobre as primeiras iniciativas de escolarização dos trabalhadores adultos na capital mineira, Belo Horizonte. Analisa-se a mobilização em prol da construção de um grupo escolar noturno para o público masculino e a experiência de escolarização noturna das mulheres, no período que compreende o início das obras de construção da cidade e o ano de inauguração do primeiro grupo escolar noturno do Estado de Minas Gerais. Com base na História das Instituições, toma como fontes os relatórios de inspetores, legislação e correspondências diversas da Secretaria do Interior. Buscou-se conferir um sentido histórico ao protagonismo desses sujeitos e às instituições escolares noturnas consideradas no âmbito da expansão da escolarização e da modernização do Estado.

Palavras-chave: Educação de adultos; Modernização; Minas Gerais.

\section{THE ADULT WORKERS' SCHOOLING UNDER THE MODERNIZATION CONTEXT ON THE STATE OF MINAS GERAIS (1894-1917)}

\begin{abstract}
In this article we present an observation about the initials trials of adult workers' schooling on the capital Belo Horizonte. It is analyzed the mobilization aiming the construction of a night shit scholar group for men and the experience of the night shift women's schooling, in between the beginning of the city's construction and the inauguration year of the first night shift scholar group from the State of Minas Gerais. Supporting on the Institutions' History, it is considered as sources: inspectors' reports, legislation, numerous mails from the Interior Secretary. It was tried to give a historical sense to these individuals and to the night shift scholar institutions taken under the State's education expansion and modernization scope.
\end{abstract}

Keywords: Adult's Education; Modernization; Minas Gerais.

\section{Introdução}

A luta por instrução primária para os jovens e adultos trabalhadores mineiros inscreve-se nos processos históricos de construção da moderna Capital do estado, Belo Horizonte, por constar como a primeira mobilização operária de reivindicação dos benefícios proclamados pelos discursos, amplamente divulgados na época, que tinham os grupos escolares como o símbolo maior da modernidade educacional republicana ${ }^{3}$. Tal reinvindicação fez convergir dois grandes processos em curso a partir da segunda metade do século XIX, no país. Por um lado, no contexto de afirmação dos ideais republicanos, a construção da nova Capital $^{4}$ sinalizava para um processo de transformação que vinha inspirando a elite brasileira, desde o final do século XIX, a imbuir-se de um projeto "que 
prometia romper com os laços de uma sociedade que permanecera, até então, encastelada em moldes arcaicos e conservadores" e a prosseguir em busca de uma nova ordem "enraizada em um padrão civilizatório moderno" (JULIÃO, 2011, p. 116). Nesse contexto, encontram-se os "traços" que demarcam o processo de modernização da sociedade mineira passando, necessariamente, pela construção planejada da cidade e, bem assim, pela instauração de novas práticas sociais e modos de vida articulados "sobre a mudança, a inovação, mas também sobre a inquietude, a mobilização contínua, a subjetividade movediça, a tensão, a crise" (BAUDRILLARD, 1977, p. 140).

Por outro, tem-se nesse período, no âmbito das relações de produção, "um duplo movimento de consolidação: o da mundialização do capitalismo, e o da inserção do Brasil nesse processo", ainda que de forma parcial (CHAMON; GOODWIN, JR., 2012, p. 321). Tal processo intensificou as preocupações e criação de medidas relativas ao trabalho, pois "cada vez mais, tornava-se fundamental garantir e qualificar a mão de obra para lidar com novas técnicas, ferramentas, máquinas, e para se inserir em um novo ambiente de trabalho" (p. 322). Nesse movimento, evidencia-se também o denominador comum entre as nações modernas: a "era da produtividade: intensificação do trabalho humano e da dominação humana sobre a natureza, um e outro reduzidos ao status de forças produtivas e aos esquemas de eficácia e de rendimento máximos" (BAUDRILLARD, 1977, p. 140).

Carlos Alberto Oliveira (2011), ao analisar o ideal de sociabilidade na Capital, reconhece no processo de ocupação, reorganização e ressignificação dos espaços públicos em Belo Horizonte até a década de 1930, três temporalidades. A primeira, "de 1897 a 1910, se refere ao processo de consolidação da mudança da capital do estado que atraiu levas de trabalhadores de várias regiões de Minas e imigrantes estrangeiros. De fato, em Minas, desde meados do século XIX, era notória a presença de grupos de trabalhadores livres que somados aos imigrantes europeus, em especial aos italianos - mão de obra instruída e qualificada - atraídos pela política imigratória do Estado, constituíam um grande contingente populacional. Esse processo imigratório também trouxe moradores de outras cidades e estados brasileiros. Deivison Gonçalves Amaral (2011, p. 4) corrobora afirmando que,

[...] por ocasião da construção da cidade, uma grande quantidade de homens e mulheres se deslocou para a região do Curral Del Rey para trabalhar nas obras. Entre os trabalhadores que vieram para Belo Horizonte no início de sua construção foi significativa a presença de imigrantes estrangeiros, que vieram para trabalhar em colônias agrícolas ao redor da cidade e também como trabalhadores qualificados na construção civil.

No período seguinte, de 1910 a 1920, em face ao grande fluxo de migrantes tem-se a criação de medidas regulatórias de ocupação dos limites internos da cidade (OLIVEIRA, 2011, p. 1). É também um período de criação de espaços de sociabilidades como os cafés, os teatros e cinemas que, no período seguinte, se difundem por toda a cidade. Toda essa movimentação provoca o crescimento acelerado da população que, em 1906 contava com 17.615 moradores; seis anos depois esse número passou para 38.822, o que correspondeu a um aumento de $120 \%$, ou seja, uma média de $20 \%$ anualmente. Tal crescimento encontra explicação, ainda na análise de Oliveira (2011, p. 1) que reconhece "de 1910 a 1920 o segundo impulso de migração populacional para a nova capital, ligado à crescente industrialização através do desenvolvimento da indústria têxtil e de alimentos e bebidas". Em 1912, 11,3\% da população de Belo Horizonte era composta por estrangeiros, em 
maioria proveniente da Europa. Desse universo, 67,67\% eram italianos (AMARAL, 2011, p. 6).

O crescimento populacional, principalmente com a chegada desses imigrantes provocou uma "convivência súbita, socialmente tensa e conflituosa, com o estrangeiro, um estranho com uma identidade mais definida". Com isso, novas relações sociais foram construídas e novas demandas foram incorporadas à vida da pacata população que ali vivia (ANDRADE, 1997, p. 192). Dentre tais demandas, inclui-se, especialmente, a luta por moradia e por educação.

\section{Moradia e educação na pauta dos movimentos dos trabalhadores da Capital}

Diversos estudos já se dedicaram ao tema da urbanização ou da ocupação de Belo Horizonte destacando a preocupação com a delimitação espacial da cidade em conformidade com a condição social dos seus moradores ${ }^{5}$. Conciliar os desejos da elite política que encarava o advento da República como sinal de uma ruptura com o passado, preconizando a modernização e o desenvolvimento nacional, com o desenvolvimento urbano-social fez com que a solução para a concretização da sonhada modernidade plasmasse-se logo na planta da Capital que, ao fazer a divisão do espaço, determinou também a hierarquização social de sua ocupação:

[...] na planta resolve-se, portanto, sob três divisões fundamentais: zona urbana, reservada às boas famílias, aos funcionários do estado, aos comerciantes de destaque, enfim, às elites; zona suburbana, reservada para os trabalhadores pobres e antigos moradores do que então passaria a ser o centro da nova capital; e, por fim, a zona rural, em que se realizaria a pequena agropecuária de abastecimento (SIMÃO, 2008, p. 121)

A preocupação com a habitação dos operários ocupou a agenda do Governo mineiro e se transformou, imediatamente, em "uma nova questão política e social a ser resolvida" (AMARAL, 2011, p. 8). Sobre esse assunto, o autor assevera:

[...] a preocupação médico-sanitarista fez com que se idealizasse uma cidade com largas avenidas, que favorecesse o fluxo de pessoas e fosse suficientemente arejada para que o vento afastasse os miasmas. Ademais, o projeto original não permitia a fixação da população trabalhadora, estrangeira ou não, na zona urbana da cidade, que era delimitada pela Avenida do Contorno, um "cordão sanitário" que circundava Belo Horizonte. Os preços dos lotes eram bastante elevados, e as exigências feitas aos compradores tornavam a compra possível apenas para pessoas com boas condições financeiras, o que não era uma característica dos migrantes e imigrantes recém-chegados para trabalhar na construção da cidade (AMARAL, 2011, p. 4) ${ }^{6}$.

Ao mesmo tempo em que os braços dos operários se tornavam indispensáveis à construção da moderna capital, a vigilância recaia sobre eles, com vistas a garantir uma ocupação controlada e a manutenção da ordem. Nesse sentido, tal questão

[...] não fugiu ao objetivo primeiro dos idealizadores da cidade, que era o de manter a utopia de uma cidade moderna, hierarquizada e construída para os administradores públicos e para as elites em geral. Visto que para as elites políticas não interessava uma ocupação desordenada da cidade e muito menos uma classe trabalhadora insatisfeita, que pudesse se revoltar e atentar contra a ordem pública, o problema das habitações populares se constituiu como urgente questão política. 
Entretanto, a despeito da preocupação com a ordem e a segurança, Marian Guedes Costa e Silva (2008, p. 6) destaca que

Os limites da Avenida Contorno não eram os limites para a circulação das pessoas. A área urbana e suburbana, apesar de bem definida no projeto, era habitada tanto pelas elites quanto pelos chamados operários. $\mathrm{O}$ footing na Avenida Afonso Pena era frequentado por "gente de bem" e por "gente de segunda classe". Operários frequentavam os cinemas e escreviam artigos nos jornais defendendo a censura cinematográfica imposta pelo governo. Pode-se dizer que uma sensibilidade era partilhada. Ou seja, além de espaços, as pessoas compartilhavam normas e condutas morais. $(2008$, p.6)

Embora separados pela Avenida do Contorno, "cordão sanitário" da cidade, os trabalhadores foram, assim, se apossando da cidade e, nas zonas suburbanas, construindo os primeiros bairros operários. Em 1909, o Governo demarcou, na região do Barro Preto, a primeira vila destinada a esses sujeitos. Apesar disso, "outras regiões na zona urbana e suburbana já eram ocupadas por trabalhadores em condições precárias", como "a região da Barroca, que desde 1902 já era reclamada pelos trabalhadores" e já contava com uma população de quase 2000 pessoas ali morando em condições difíceis (AMARAL, op. cit., p. 9).

Como parte do movimento de ocupação desse espaço racionalmente determinado, logo aí viriam a se instalar as primeiras escolas noturnas para atendimento aos operários. Como iniciativa associativista ${ }^{7}$ tem-se a Escola Noturna, criada e mantida pela Confederação Auxiliadora dos Operários de Minas Gerais. Fundada no dia 12 de março de 1905, a Confederação se apresentou à sociedade e aos trabalhadores como um "organismo sem militância político-partidária", cuja finalidade era agregar o operariado mineiro e "manter um clima de harmonia entre operários, industriais ou chefes"; "empregar todos os meios possíveis de resolver qualquer divergência entre operários" e patrões. ${ }^{8}$ Dentre os seus princípios, constavam a "filantropia, sociabilidade, instrução, ordem e progresso" (CONFEDERAÇÃ̃..., 1911, p. 1). De inspiração socialista, a Confederação atuava no sentido de solucionar as questões sociais por meio da filosofia positivista, evitando a desordem social e política, defendendo a tutela do Estado como "protetor e defensor" dos operários, por considerar "a classe trabalhadora incapaz de se constituir como força social" (PASSOS, 1986, p. 49).

Nas páginas do seu porta-voz explicitavam-se aos trabalhadores e à toda sociedade mineira os princípios subjacentes à concepção de luta na qual a Confederação pautaria a sua ação política em vista da garantia da harmonia social. Inspirada numa perspectiva sociológica funcionalista, ressaltava o papel do Estado como regulador e garantidor do cumprimento dos contratos estabelecidos entre os membros do organismo social:

o que as constituições não podem fazer, realizará até certo ponto o Estado, cuidando de tornar seguros e respeitados os direitos de todos, distribuindo prodigamente a instrução e favorecendo a atividade dos cidadãos, desconhecidos os privilégios que corrompem e estragam o organismo social. ${ }^{9}$

Cientes e compartilhando dos discursos que enalteciam o lugar ocupado pela instrução pública no curso de modernização do país, os operários envidaram esforços e reivindicaram do Estado a construção de um grupo escolar, especialmente, para atendê-los. A crença difundida no país, e em Minas não foi diferente, era a de que essa modernização viria por meio da renovação do ensino, espelhada nas diversas experiências em 
desenvolvimento nos contextos europeus e norte-americanos de criação dos modernos e suntuosos grupos escolares ${ }^{10}$. Sob os auspícios de uma nova "forma escolar" (VINCENT; LAHIRE e THIN, 2001), eles se legitimavam como elementos distintos da modernidade educacional, visto que, no

[...] momento em que o processo de urbanização, a construção material e simbólica de Belo Horizonte era tida e confundida com o próprio movimento de modernização, os profissionais e agentes da educação souberam captar a possibilidade de identificar a nova escola que se queria construir com esse movimento, projetando e construindo - entre práticas e representações - uma escola urbana e de massas (FARIA FILHO, 2000, p. 37)

E nesse sentido, a planejada Capital, símbolo e concretização da modernidade republicana, da racionalidade, da ruptura com o velho, com o caótico e com a desordem, não poderia conviver com um modelo retrógrado de organização do ensino primário, expresso pelas escolas isoladas, cujo modelo precisava ser extirpado para dar lugar ao novo, ao que havia de mais moderno em termos de educação: os grupos escolares ${ }^{11}$. Os argumentos em defesa da implantação desse modelo de instituição escolar se fundamentavam nos pressupostos de uma vantagem econômica de racionalização, de higiene e de promoção do novo, assim, num projeto de visibilidade e de projeção dos ideais republicanos, por meio da construção de prédios próprios para abrigar os símbolos da modernidade com um programa arquitetônico diferenciado cujo objetivo era identificálos como espaço público de escolarização (BENCOSTTA, 2005) ou, bem assim, como "monumentos" para enaltecimento da República (FARIA FILHO, 2000), ou ainda como "templo de civilização" (SOUZA, 1998).

Privilegiada pelo investimento de modernização da educação, levado a efeito pela Reforma da Instrução Pública Primária, no governo de João Pinheiro da Silva ${ }^{12}$, a Capital acolheu os primeiros grupos escolares construídos no Estado de Minas Gerais: o $1^{\circ}$ grupo escolar, denominado, posteriormente, Grupo Escolar Barão do Rio Branco, foi criado em 1906, e o $2^{\circ}$, Afonso Pena, em 1907. Nesse ano, o estado de Minas Gerais também contava com "dois em Juiz de Fora e um em cada uma das cidades de São João Nepomuceno, Araçuaí, Lavras e Passa-Quatro", totalizando oito novos estabelecimentos de ensino (GONÇALVES, 2006, p. 119). Dando prosseguimento, na Capital, em 1909, foi criado o $3^{\circ}$, Grupo Escolar Cesário Alvim; o 4º , Grupo Escolar Francisco Salles, em 1911 e, em 1917, o $8^{\circ}$ Grupo Escolar, denominado Assis das Chagas ${ }^{13}$, que se constituiu o objeto da luta dos operários mineiros, a qual aqui trataremos.

\section{Mobilização dos operários para construção do grupo escolar noturno}

O grupo escolar noturno "Assis das Chagas" inscreve a sua história no primeiro movimento político de reivindicação por escola, organizado pelos operários mineiros que trabalhavam na Capital. O objetivo da reivindicação era transformar a Escola Noturna da Confederação Auxiliadora dos Operários de Minas Gerais no primeiro grupo escolar noturno do Estado.

Coerente com os princípios da Confederação e certos de receber a instrução, "prodigamente distribuída pelo Estado", deu-se início a um longo processo de negociação no sentido de obter a transformação desejada. Dessa forma, a negociação, estabelecida ao longo do ano de 1912, contou com o apoio do presidente do Estado de Minas Gerais, Júlio Bueno Brandão e do Secretário do Interior e Justiça, Delfim Moreira da Costa Ribeiro. 
Para tratar do assunto, nomeou-se uma comissão assim apresentada ao Governo, pelo presidente da Confederação, Augusto Berardo Nunam:

Exmo. Snr. Júlio Bueno Brandão, digníssimo presidente do estado de Minas. Tenho a honra de apresentar a V. Ex. ${ }^{a}$ a comissão de operários, nomeada em assembleia geral de 14 do corrente mês, para entender-se com V.Exa. sobre a criação de um grupo escolar noturno, que é de grande necessidade para a classe operária. Saúde e fraternidade. Belo Horizonte, 24 de julho de 1912 (MINAS GERAIS, 1912).

Disposto a atender ao pedido, o presidente do Estado mobilizou a Secretaria do Interior no sentido de tomar as devidas providências para atendimento à reivindicação dos operários:

Convém incumbir o inspetor regional de abrir uma matrícula provisória para verificar se é possível a manutenção de um grupo escolar noturno. Faça-se uma nota neste sentido por ser publicado no Minas, dando conta da resolução (MINAS GERAIS, 1912).

Na ausência de barreiras entre os operários e o Poder Público, Berardo prosseguiu com a negociação junto ao Secretário Delfim Moreira, encaminhando, com base nas experiências acumuladas pela associação, um ofício contendo importantes sugestões para a criação do referido grupo escolar noturno. Uma das primeiras recomendações foi a de que o Grupo Escolar fosse uma ampliação da Escola Noturna mantida pela Confederação ${ }^{14}$. Estabelecendo os termos de uma parceria, sugeriu que a matrícula ficasse a cargo de um "funcionário de confiança do governo" e que fosse realizada na Sede da associação, onde havia "frequência habitual dos operários", no horário das "seis horas da tarde às nove da noite, porque os operários, durante o dia trabalham, portanto impossível que possam a outra qualquer hora, se achar livres para tal fim". Sugeriu, ainda, que fossem aceitos à matrícula somente os homens, na faixa etária de 14 a 40 anos de idade ${ }^{15}$, que pudessem comprovar a condição de operário por meio de "um atestado do chefe, mestre de oficinas ou patrões, onde trabalham". Essa condição definia a natureza da instituição que se pretendia criar e estabelecia os contornos de sua identidade e da de seu público, em particular, isto é, uma escola operária. A relação harmoniosa com o Poder Público também se garantiria a partir das seguintes sugestões:

que a administração do grupo, sujeita a rigorosa inspeção do Governo, seja, gratuitamente, exercida pela Confederação e esta, sempre de acordo com o Governo, nomeará os professores que tenham a necessária competência para o exercício do magistério (BERARDO NUNAM,1912).

Como se pode ver, o que Berardo Nunam propunha era o estabelecimento de uma grande parceria na criação do primeiro grupo escolar noturno para os trabalhadores mineiros, para o qual a Confederação disponibilizaria ainda "um prédio com um vasto salão, dois gabinetes, bem servido de boa instalação elétrica e sanitária, um grande terreno murado, onde se poderá, com muita folga, construir outros salões". Para concluir o intento de "ver disseminada a instrução entre os membros da classe operária", solicitou ao Governo, um auxílio mensal apenas para a manutenção dos professores e para aumento do prédio, esperando, assim, alcançar "todos os benefícios que a classe sedenta de luz espera receber de vossas mãos” (BERARDO NUNAM, 1912).

No correr das negociações, entretanto, o sonho de levar as luzes à classe sedenta, começou a se tornar distante, pois, num procedimento de praxe da Secretaria, ao sumariar 
o ofício, referido anteriormente, o funcionário Marinho Carvalhães desaconselhou o Secretário, colocando em dúvida o benefício de tal empreendimento:

[...] convém esperar o resultado da matrícula recentemente aberta a fim de se verificar o número de operários que desejam receber instrução. [...]. As condições que a Confederação pretende impor não são aceitáveis: ou o governo concorre apenas com a verba destinada à manutenção dos professores e aumento do prédio, correndo a administração exclusivamente por conta da Confederação e limitando-se o governo à fiscalização, ou cria o grupo e assume a inteira administração dele. (CARVALHÃES, 1912).

Suas palavras seguintes deixam entrever certo receio em entregar um dos maiores símbolos da modernidade republicana aos operários: "não nos parece feliz a ideia de criação de grupo para a ministração do ensino aos operários. Seria melhor a criação de escolas agrupadas". A reunião das escolas isoladas num único prédio - modelo sugerido pelo funcionário - remetia a um passado que os grupos escolares estavam destinados a superar por simbolizarem o atraso e o obsoleto na educação. Com seu "gesto de interpretação" (ORLANDI, 2001), o funcionário acabou produzindo novos sentidos para a petição dos operários, dando à sua análise uma força insinuadora capaz de colocar em dúvida a própria viabilidade do projeto requerido pela Confederação. Assim, de forma bastante convincente, e já contando com a possibilidade de o Secretário atender às suas sugestões, desconsiderou a experiência adquirida pela Confederação, e insistiu na necessidade da realização de um teste:

o instituto funcionará, em começo a título de experiência, independente do ato de criação, recebendo os professores e empregados os seus vencimentos por meio de requisições especiais, feitas mensalmente. Se surtir efeito será então criado definitivamente de acordo com as necessidades verificadas pela experiência. São estas as providencias que a seção pode sugerir (CARVALHÃES, 1912).

O efeito que se seguiu foi produzido por outro funcionário, também contrário ao projeto dos operários, o inspetor da Capital, Antônio Gomes Horta, que desconsiderou as recomendações da Confederação em relação ao principal ponto da negociação: as condições da matrícula. $\mathrm{O}$ relato do inspetor técnico auxiliar, da $1^{\mathrm{a}}$ circunscrição regional do Estado, Joaquim José Pedro Lessa, revelou a manobra política adotada para pôr a termo os sonhos dos trabalhadores:

[...] compareci ao edifício do $2^{\circ}$ Grupo Escolar desta capital desde o dia 6 até o dia 17 do corrente mês para constatar de conformidade com ato regimental [...] o período de adaptação para a experiência da matrícula, de conformidade com o edital expedido foi das 7 às 11 da manhã, verificando-se o fato de não comparecerem alunos senão um, que procurou o domicílio do digno inspetor sr. Gomes Horta que enviou a nota de matrícula à Secretaria do grupo aludido (PEDRO LESSA, 1912, grifos nossos)

O relatório evidencia a ação fraudulenta dos funcionários da Secretaria do Interior em relação aos propósitos da Confederação, pois, como visto anteriormente, a indicação do local para a matrícula era a sua Sede, por ser "o lugar onde há frequência habitual dos operários", bem como o horário de "seis às nove da noite, porque os operários, durante o dia trabalham, portanto, impossível que possam a outra qualquer hora, se achar livres para tal fim". Essas sugestões visavam, justamente, a atender às exigências impostas pela rotina 
de trabalho dos operários. Situação, entretanto, que não passou despercebida pelo inspetor técnico que, reconhecendo os equívocos na condução do processo, assim se pronunciou:

[...] entendi, desde logo, que o período determinado para essa estatística era menos conveniente e contrário aos interesses naturais dos alunos em questão: operários, homens do trabalho, restritos ao horário exigido (muito cedo) pelos centros industriais e de serviço também público, ocorrendo justamente das 6 horas do dia em diante (PEDRO LESSA, 1912).

Ao cientificar os fatos à Secretaria do Interior, o inspetor Gomes Horta, ocultando as ordens que dera para realização da matrícula, destacou com desfaçatez o suposto "desinteresse" dos operários:

[...] fiz publicar edital no órgão oficial do Estado abrindo a matrícula provisória de alunos a fim de verificar a possibilidade da criação de um grupo escolar para adultos nesta capital. Esgotando o prazo regulamentar só um candidato solicitou a sua inclusão. Nestas condições nenhuma informação mais cabe-me apresentar a V. Ex. ${ }^{a}$ a quem para o caso, aguardo novas ordens. Saúde e fraternidade. Belo Horizonte, 30 de agosto de 1912 (GOMES HORTA, 1912, grifos nossos)

O desfecho dessa negociação pode ser inferido ao se constatar que o primeiro grupo escolar noturno, do Estado de Minas Gerais, somente se transformou em realidade no ano de 1917, na gestão de Delfim Moreira da Costa Ribeiro, como Presidente do Estado, ou seja, cinco anos depois. Certo é que, por questões menos administrativas que políticas, o tão sonhado monumento republicano não se concretizou como objeto de luta dos operários mineiros à época.

\section{A escola noturna feminina da Capital}

As mudanças sociais em curso em todo o país alçaram a instrução pública e a educação ao centro das atenções das elites políticas brasileiras. Em Minas não foi diferente, como bem destacou o secretário do Interior Delfim Moreira da Costa Ribeiro:

[...] as necessidades físicas, morais e intelectuais do homem, o desenvolvimento notável observado na ordem política e social da nacionalidade e do Estado e o progressivo desdobramento do trabalho em suas diversas manifestações econômicas, tornando cada vez mais intensas e complicadas as relações sociais, fundamentam a necessidade absoluta de instruir e educar o povo para todas as emergências da vida atual e futura e colocam o problema educativo no primeiro plano, como questão vital de uma nação (RIBEIRO, 1911, p. 25)

Embora tal consideração, mediante a frustrada negociação dos operários mineiros, pareça contraditória, visto que os trabalhadores que se dedicaram à construção da moderna cidade não obtiveram êxito em seu projeto de reivindicação de escolarização pública, a situação para as mulheres trabalhadoras evidencia uma situação de franco sucesso. Compreendida como parte de um processo indispensável de construção de valores e de concepções subjetivas atinentes ao projeto de modernização social e cultural, no que tange às mentalidades e aos costumes da população, a escolarização das mulheres pobres da Capital, obteve uma atenção especial por parte da elite política mineira.

Concomitantemente às negociações entre os operários e o Governo, no ano de 1912, a Capital passou a contar com a existência de uma escola noturna ${ }^{16}$ dedicada 
exclusivamente ao público feminino aos cuidados da professora Zélia Rabello. Coerente com os princípios de planejamento da ocupação urbano-social da Capital, a escola situavase na zona destinada aos operários, ocupando as dependências do $3^{\circ}$ Grupo Escolar, denominado Cesário Alvim.

Pelas informações contidas no primeiro relatório enviado ao Secretário do Interior, em 21 de dezembro de 1913, pela diretora do $3^{\circ}$ Grupo, Anna Cintra de Carvalho, pode-se supor que a intenção inicial do Governo era a de que a escola funcionasse por um tempo determinado, o que foi desaconselhado pela diretora:

[...] verifiquei que há necessidade da continuação das escolas, ao menos até diminuir o número de analfabetos ainda existentes, tendo o governo por base a redução do número de alunas matriculadas no princípio de cada ano, o que, fatalmente, se dará, em vista do empenho da instrução aqui na Capital, com a criação constante de Grupos e escolas isoladas (CARVALHO, 1914)

O que se verificou, ainda foi que o crescimento da demanda feminina por instrução primária levou à ampliação do número de classes - que passaram de duas para cinco - e à consequente transformação da escola noturna isolada em escola noturna agrupada, recebendo a denominação de Curso Noturno Feminino da Capital. Organizado nos moldes das escolas agrupadas - tal como sugerido pelo funcionário, Marinho Carvalhães, em relação às reivindicações dos operários - o Curso foi oficialmente criado em 05 de janeiro de 1914, pelo Decreto de $\mathrm{n}^{\mathrm{o}}$. 4088, assinado pelo então Diretor da Secretaria do Interior, Dr. Francisco de Assis das Chagas Rezende ${ }^{17}$, e instalado a 02 de fevereiro do mesmo ano. Com duração total de dois anos, funcionava de segunda-feira a sábado, com exceção das quintas-feiras, no horário das 18:30 às 21 horas (MINAS GERAIS, 1914. p. 10).

Assumir a direção do Curso Noturno Feminino significava para a diretora Anna Cintra a incorporação de uma terceira jornada de trabalho, o que a levou a indicar para ocupar o cargo a fundadora da escola feminina, conforme se expressou ao Secretário do Interior:

[...] ora, como o meu trabalho foi dividido em 2 turmas, verifiquei que o acúmulo de serviço de mais um $3^{\circ}$ turno, sob a minha responsabilidade acarretaria prejuízo à minha saúde e ao trabalho noturno; por isto resolvi, depois das aulas instaladas, agradecer a V. Ex ${ }^{\text {cia }}$ a consideração e pedir a minha dispensa do lugar de diretora, para o qual deveria ser chamada a professora Zélia Rabello por ter sido a fundadora do Curso Noturno (CARVALHO, 1914).

Porém, seu pedido não fora aceito, como destacou: "fiz, embora com sacrifício, o que foi possível para sustentá-las [às aulas], afim de que o resultado compensasse os sacrifícios do governo" (CARVALHO, 1914).

Os primeiros dados relativos à matrícula da Escola feminina nos colocam diante de uma realidade que extrapola o seu significado estatístico e revelam uma situação inusitada, se considerada no contexto da jovem e moderna Cidade, ainda em franco processo de construção e de ocupação urbano-social. No seu primeiro ano de funcionamento contava com cinco turmas e uma matrícula de 361 alunas, sendo a frequência média em torno de 115, no primeiro semestre, e 120 no segundo. Chama-nos a atenção esses dados, pois evidenciam uma presença expressiva dessas mulheres - a maioria de nome Maria ${ }^{18}$ percorrendo, do burburinho à calada da noite, as ruas de uma cidade ainda em construção, como descrita por Júlia Calvo (2013, p. 89): 
[...] ocupada por gente de toda parte. Braços trabalhadores que ainda tornavam-se necessários para o grande canteiro de obras e a manutenção dos serviços que a cidade apresentava; funcionários e burocratas para gerir o novo e ordenar a grande cidade; profissionais liberais da saúde, da construção, do comércio e de todo lugar para caracterizar o moderno e dar funcionalidade; gente para encher as ruas longas e largas, para ocupar os bancos da universidade, as mesas do bar, as cadeiras do bonde, do cinema, do teatro.

A presença das mulheres pobres ocupando os bancos escolares e se deslocando para as aulas noturnas, demonstra uma ruptura no imaginário social que permeava a sociedade brasileira nas décadas iniciais do século XX, em relação à ocupação dos espaços públicos que, historicamente, foram legitimados ao sexo masculino ${ }^{19}$. A julgar pelos comportamentos da elite da época, que ainda hesitava "em trocar o ambiente da casa pelo convívio da rua, que lhes parecia ameaçador", confirma-se que esse não era o público que por ali passava todas as noites, de segunda a sábado, em direção à escola noturna, pois "transitar pela cidade significava expor-se publicamente, arriscar-se a toda sorte de encontros e situações novas e imprevisíveis" (JULIÃO, 1996, p. 66). Deslocamento que poderia, por um lado, significar a oportunidade de adesão aos novos valores que inspiravam a construção da cidade moderna, pois,

a capital mineira significava, nas primeiras décadas do século $\mathrm{XX}$, a possibilidade de começar a vida numa cidade nova, portanto cheia de oportunidades e também de evidentes carências da cidade imberbe que se estabelece. Significava adotar o estilo de vida metropolitano, com seus confortos, mas com padrões de consumo e organização que impunham modos de ser e viver próprios de Belo Horizonte (CALVO, 2013, p. 89)

Mas, por outro, poderia também, revelar permanências e dificuldades que ainda persistiam para as mulheres que viviam numa sociedade marcadamente conservadora e patriarcal, como a brasileira, como pode ser inferido a partir da justificativa que a diretora Anna Cintra apresentou à Secretaria para explicar a baixa frequência às aulas noturnas, em relação à frequência do curso diurno. Para a diretora, "maior seria o resultado, se não fossem as dificuldades naturais das alunas que as frequentam". Nesse sentido, naturalizando a condição social das alunas trabalhadoras, prosseguiu nas suas argumentações: "ora deixam de frequentar, porque proíbem os patrões, ora pela distância e falta de companhia" (CARVALHO, 1914).

Esses motivos deixam entrever duas dimensões inerentes à condição daquelas alunas - o pertencimento social e de gênero: dividir o tempo da escola com o tempo do trabalho e não poder percorrer as ruas, ainda bastante sombrias da jovem Cidade, à noite, desacompanhadas, principalmente sem uma companhia masculina. E não eram poucas, as Marias que frequentavam a Escola, como se pode ver: a classe de primeiro ano, regida pela professora Maria da Glória Moura Costa, contava com 42 alunas (1914); a de segundo ano, regida pela professora Angélica Maria de Almeida, tinha 40 alunas (1914); a de segundo ano, regida pela professora Regina Breyner, tinha 36 alunas (1915); e a de primeiro ano, regido pela professora adjunta Georgina Amélia de Carvalho, tinha 41 alunas (1915) ${ }^{20}$.

Essa observação corrobora o sentido atribuído por Letícia Julião (1996) à travessia noturna da cidade, evidenciando, entretanto que os "perigos noturnos" também afetavam a população feminina pobre. Situação que gerava transtornos, não somente para as alunas como também para a própria manutenção das aulas noturnas, pois implicava diretamente na frequência sobre a qual, advertiu Anna Cintra: "por maior que seja a matrícula, é 
impossível exigir-se a mesma frequência exigida para as escolas diurnas". Com base na rotina das alunas e nas implicações pedagógicas dessa situação, a diretora sugeriu mudanças nas normas para o curso noturno: "devido ao pouco tempo para o ensino, que é para menos da metade do que têm as outras professoras do curso diurno, a frequência também exigida deveria ser proporcional ao tempo, isto é, o mínimo de $15 \mathrm{em}$ vez de 30 ”. Não restam dúvidas de que tal situação indiciava os paradoxos daquela cidade moderna, a qual ainda "permanecia vinculada aos muros, ao afetivo e provincial, marcadamente, nos grupos e na relação entre os grupos da cidade, conservando valores herdados do período imperial e colonial brasileiro" (CALVO, 2013, p. 86).

O que as várias "Marias" da Escola Noturna Feminina fizeram foi desafiar os padrões patriarcais e hierarquizantes da época, evidenciando a adesão aos novos comportamentos, coerentes com a idealização da Cidade, onde novas relações sociais foram estabelecidas e novos contatos sociais e culturais aconteceram, incorporando, assim, novos valores, construindo novas subjetividades, novas sensibilidades e disposições mentais, inclusive de modo a diminuir as diferenças culturais em relação ao homem. Tudo isso, na verdade, poderia representar também os paradoxos ou contrastes da nova Capital, como mostrou Julia Calvo (2013, p. 68):

A cidade moderna é representada assim como um lugar de contrastes: pobreza-riqueza, degradação-opulência, ordem-caos, liberdade-controle e assim sucessivamente, que se traduzem na grande diversidade que marca a cidade formada pela heterogeneidade de grupos, de profissões, de nacionalidades.

\section{Do sonho dos operários à "transgressão das Marias": o tão sonhado grupo escolar noturno}

O sucesso das aulas ministradas no Curso Noturno Feminino foi um fator determinante na decisão política do Governo mineiro de, não somente ampliar o número de turmas, como também, em consequência, transformá-lo no tão desejado Grupo Escolar. Dessa forma, no mês de março de 1917, às cinco classes femininas existentes foram agrupadas duas novas para, finalmente, incluir os trabalhadores da Capital, dando origem ao primeiro Grupo Escolar Noturno do Estado de Minas Gerais. Criado pelo Decreto $\mathrm{n}^{\mathbf{o}}$ 4.726, sob a direção da farmacêutica Elysena Costa, o Grupo Escolar Noturno funcionou nas mesmas dependências do $3^{\circ}$ Grupo Escolar pelo longo período de duas décadas, até ser transferido para outro prédio, onde já também funcionava o Grupo Escolar Olegário Maciel, ali permanecendo até o encerramento de suas atividades, ao final da década de 60, quando teve suas turmas incorporadas pelo Grupo que o abrigava.

As mulheres professoras também marcaram presença na história do Curso noturno e, de acordo com os diversos documentos consultados (termos de visita, relatórios das diretoras e documentos internos), podemos afirmar que, durante toda a existência dessa Instituição, somente um professor ali ministrou aulas. As professoras eram todas casadas e tinham, em média, de quatro a cinco filhos, ocasionando um volume muito grande de pedidos de licença, em função da maternidade ou de doença dos filhos.

A constatação da presença feminina na direção das escolas ou compondo o corpo docente não era, entretanto, uma novidade, pois Faria Filho já destacava esse fenômeno e a necessidade de se compreendê-lo como forma de reconstruir o "processo histórico vivido por essa categoria em termos de sua constituição social e de gênero" (2000, p. 107). Jane Soares de Almeida (1998, p. 37) comenta que, para as mulheres, o ingresso no magistério, 
a partir do final do século XIX, representava a única possibilidade de profissionalização e de se obter certa autonomia em relação aos domínios masculinos, em conformidade com os ideais propostos pelos positivistas e higienistas, bem como em consonância com o imaginário social acerca do papel feminino da época. Ressalta-se ainda que, conforme o Decreto de $\mathrm{n}^{\mathrm{o}} 3.191$, de 09 de junho de 1911, tanto às menores quanto às professoras casadas era exigida "uma autorização ou licença dos pais ou maridos ou documento judiciário equivalente" para lecionar (MINAS GERAIS, 1911, p. 193). Essa temática, porém, se destaca ainda como mais uma lacuna que incorpora as demandas de investigação sobre a história da educação dos adultos em Minas Gerais.

\section{Considerações finais}

Por fim, essa reflexão sobre os primórdios da escolarização noturna dos trabalhadores e das trabalhadoras da Capital mineira, tendo como pano de fundo o ideário de modernização que permeou as práticas sociais e políticas do Estado, nos possibilita compreender e explicar um pouco mais sobre o protagonismo desses sujeitos na construção da educação e, bem assim, da existência das instituições escolares noturnas como constitutivas da História da Educação brasileira. Também, conhecer parte do itinerário de vida de tais instituições conferindo-lhes uma identidade histórica específica construída na relação com o espaço geográfico e com as condições sociais e políticas que as condicionam (MAGALHÃES, 1999). Nesse caso, o que se percebe é que homens e mulheres, ao atuar como sujeitos na conquista do direito ao usufruto dos benefícios da educação, percorrem distintas trajetórias e, ainda que não obtenham êxito, constroem lugares históricos que confrontam as representações sobre os pobres e a pobreza no contexto da modernização urbana.

Esta análise evidencia, ainda, um contexto de luta e de disputas políticas envolvidas na trama de escolarização dos trabalhadores adultos mineiros, levando à compreensão do lugar ocupado por essa temática no imaginário daqueles sujeitos que se responsabilizaram pela construção das políticas educacionais no Estado. Além disso, a análise aqui realizada nos mostra que a preocupação com a instrução primária constou não somente da pauta do movimento operário, como também foi motivo de mobilização efetiva, por parte de uma das principais Associações defensora dos interesses da população trabalhadora. Porém, diante do insucesso da tentativa empreendida pela Confederação, de criar e gerir o primeiro grupo escolar noturno destinado exclusivamente aos operários adultos, seria razoável considerar que esses sujeitos ainda não haviam alcançado proeminência nos projetos de educação da moderna Capital do Estado.

Entrelaçando sua história à história da moderna Capital, os trabalhadores e as trabalhadoras mineiras demarcaram um lugar no projeto de modernização do Estado e se fizeram presentes nas lutas e reivindicações operárias de início do século XX. Nesse cenário, saíram vencedoras as mulheres cujas presenças maciças nas salas de aulas não somente viabilizaram a manutenção da Escola como, também, possibilitaram a concretização de um sonho que constou da pauta de reivindicações da Confederação Auxiliadora dos Operários. O conhecimento acerca da luta por educação na Capital pode ser, assim, compreendido, numa dupla perspectiva: de projeção interna, mobilizando um processo de construção que envolve os sujeitos escolares, professores (as), alunos (as) e diretoras; e de projeção externa ligada às questões de ordem política, econômica, social e cultural, etc. Nesse duplo movimento é que buscamos compreender a singularidade dessa luta e sua relação com a moderna Capital do Estado de Minas Gerais. 


\section{Referências}

ALMEIDA, Jane Soares de. Mulher e educação: a paixão pelo possível. São Paulo: UNESP, 1998.

AMARAL, Deivison Gonçalves. Regulamentação da ocupação urbana e as campanhas dos trabalhadores por habitação em Belo Horizonte. (1912-1930). In: SIMPÓSIO NACIONAL DE HISTÓRIA - ANPUH, 26., 2011, São Paulo. Anais eletrônicos... São Paulo. Disponível

em <http://www.snh2011.anpuh.org/resources/anais/14/1300644047_ARQUIVO_Comunicaca o2.pdf>.Acesso em: 21 mar 2015.

ANDRADE, Luciana Teixeira de. Ordem pública, crime e desvio em Belo Horizonte. Varia História. Belo Horizonte: UFMG, n. 18, p. 191-200, nov.1997.

ARAÚJO, José Carlos Souza. Os Grupos Escolares em Minas Gerais: A Reforma João Pinheiro (1906). In: CONGRESSO LUSO-BRASILEIRO DE HISTÓRIA DA EDUCAÇÃO: Percursos e Desafios da Pesquisa e do Ensino de História da Educação, 6. 2006, Uberlândia. Anais eletrônicos... Uberlândia: UFU, 2006 Disponível em: <http://www2.faced.ufu.br/colubhe06/anais/arquivos/19JoseCarlosSousa.pdf.> Acesso em: 15 set. 2007.

ARRUDA, Rogério Pereira. Álbum de Bello Horizonte: signo da construção simbólica de uma cidade no início do século XX. 2000. 216.f. Dissertação (Mestrado em Comunicação Social) - Universidade Federal de Minas Gerais, Faculdade de Filosofia e Ciências Humanas, Belo Horizonte, 2000.

BARRETO, Abílio. Belo Horizonte, memória histórica e descritiva. Belo Horizonte, Fundação João Pinheiro, Centro de Estudos Históricos e Culturais, 1996.

BAUDRILLARD, Jean. Modernité. In: ENCICLOPÆDIA Universalis. Vol. 11. p.139-

BENCOSTTA, Marcus Levy Albino. Arquitetura e espaço escolar: o exemplo dos primeiros grupos escolares de Curitiba (1903-1928). In: BENCOSTTA, M. Levy Albino (Org). História da Educação, Arquitetura e Espaço Escolar. São Paulo: Cortez, 2005, p. 95-140.

BERARDO NUMAM. Augusto. Secretaria do Interior do Estado de Minas. Papéis findos de agosto a dezembro de 1912. Códice: SI - 3376. Belo Horizonte: Arquivo Público Mineiro, 1912.

CALVO, Julia. Belo Horizonte das primeiras décadas do século XX: entre a cidade da imaginação à cidade das múltiplas realidades. Cadernos de História, Belo Horizonte, v. 14, n. 21, $2^{\circ}$ sem. 2013.

CARVAlHÃES, Marinho. Secretaria do Interior do Estado de Minas. $6^{\text {a }}$ secção. Papeis findos de agosto a dezembro de 1912. SI 4-1: 3376 (1912)

CARVALHO, Anna Cintra de. Secretaria do Interior do Estado de Minas. Ofícios encaminhados à Secretaria do Interior $-7^{\mathrm{a}}$ sessão. Códice: SI - 3525. Belo Horizonte: Arquivo Público Mineiro, 1914.

CHAMON, Carla Simone; GOODWIN JR. James William. A incorporação do proletariado à sociedade moderna- a Escola de Aprendizes Artífices de Minas Gerais (1910-1941). Varia História, Belo Horizonte, vol. 28, nº 47, p.319-340, jan/jun 2012. 
CONFEDERAÇÃO AUXILIADORA DOS OPERÁRIOS DO ESTADO DE MINAS. Constituição. Belo Horizonte: Arquivo Público Mineiro, 1919.

COSTA e SILVA, Marina Guedes. Polícia e pobreza: educação do corpo nos espaços de sociabilidade de Belo Horizonte (1897-1920). In: CONGRESSO BRASILEIRO DE HISTÓRIA DA EDUCAÇÃO, 5., 2008, Aracaju. Anais... Aracajú, UFS/UNIT, 2008. Disponível em: <http://www.sbhe.org.br/novo/congressos/cbhe5/pdf/792.pdf.> Acesso: jul. 2014.

FARIA FILHO, Luciano Mendes de. Dos pardieiros aos palácios: cultura escolar e urbana em Belo Horizonte na Primeira República. Passo Fundo: UPF, 2000.

GOMES HORTA, Antônio. Secretaria do Interior do Estado de Minas. SI 4-1: 3384 (1912). Belo Horizonte: Arquivo Público Mineiro, 1912.

GONÇALVES, Irlen Antônio. “Cultura escolar”: práticas e produção dos grupos escolares em Minas Gerais (1891/1918). Belo Horizonte: Autêntica, 2006.

JULIÃO, Letícia. Itinerários da cidade moderna (1891-1920). In: DUTRA, Eliane de Freitas; BANDEIRA DE MELO (Org.). BH: Horizontes históricos. Belo Horizonte: C/ Arte, 1996. p. 49-119

JULIÃO, Letícia. Sensibilidades e representações urbanas na transferência da Capital de Minas Gerais. História (São Paulo) v.30, n.1, p.114-147, jan/jun 2011 ISSN 1980-4369.

MAGALHÃES, Justino. Breve apontamento para a história das instituições educativas. In SAFELICE, José Luís, SAVIANI, Demerval \& LOMBARDI, José Claudinei (orgs.). História da Educação: perspectivas para um intercâmbio internacional. Campinas, SP. Autores Associados, 1999, p.67-72

MINAS GERAIS. Coleção de Leis e Decretos. Belo Horizonte: Arquivo Público Mineiro, 1910 a 1930.

NOGUEIRA, Vera Lúcia. A Escola Primária Noturna em Minas Gerais (1891-1924). Belo Horizonte: Mazza Edições, 2012.

NOGUEIRA, Vera Lúcia. A Escola Primária Noturna na Política Educacional Mineira - 1891/1924. 2009. Tese. (Doutorado em Educação). Faculdade de Educação da Universidade Federal de Minas Gerais, Belo Horizonte, 2009.

NOGUEIRA, Vera Lúcia. Mulheres adultas das camadas populares: a especificidade da condição feminina na busca da escolarização. 2002. Dissertação (Mestrado em Educação) - Faculdade de Educação da Universidade Federal de Minas Gerais, Belo Horizonte, 2002.

OLIVEIRA, Carlos Alberto. As praças e o desenho da cidade: O ideal de sociabilidade nos espaços públicos da Nova Capital de Minas nos primeiros trinta anos. In: Simpósio Nacional De História - ANPUH, 26., 2011, São Paulo. Anais... São Paulo, 2011. Disponível em <http://www.snh2011.anpuh.org/resources/anais/14/1300628001_ARQUIVO_C_A_O_tex toanpuh2011.pdf.> Acesso em: jul. 2014.

ORLANDI, Eni P.. Análise de discurso: princípios e procedimentos. Campinas: Pontes, 2001.

PASSOS, Daniela Oliveira Ramos dos. A formação urbana e social da cidade de Belo Horizonte: hierarquização e estratificação do espaço na nova capital mineira. In: 
Temporalidades - Revista Discente do Programa de Pós-graduação em História da UFMG, vol. 1, n. ${ }^{\circ}$ 2, ago./dez. 2009.

Disponível em:<www.fafich.ufmg.br/temporalidades>. Acesso: 10 mar. 2015.

PASSOS, Daniela Oliveira Ramos dos. Instituições sociais e a possível resolução do problema da ação coletiva: um estudo das associações trabalhistas de Belo Horizonte no início do século XX. Teoria \& sociedade no 22.2 - julho - dezembro de 2014, p. 187-217.

PEDRO LESSA, Pedro. Secretaria do Interior do Estado de Minas. Papéis findos de agosto a dezembro de 1912. Códice: SI - 3376. Belo Horizonte: Arquivo Público Mineiro, 1912.

RIBEIRO, Delfim Moreira da Costa. Secretaria do Interior do Estado de Minas. Rascunhos de ofícios n. 10. $7^{\text {a }}$ secção. Setembro a dezembro de 1911. Códice: SI ${ }^{-} 3819$. Belo Horizonte: Arquivo Público Mineiro, 1911.

SANTOS, Suellen Dayse Versiani dos. A casa brasileira do século XIX e seus desdobramentos na produção residencial de Belo Horizonte: influência dos antecedentes coloniais e o papel do neoclassicismo e do ecletismo. 2011. Dissertação (Mestrado em Arquitetura e Urbanismo). Belo Horizonte: UFMG, 2011.

SIMÃO, Fábio Luiz Rigueira. Tradição e modernidade na construção da nova capital mineira: o Padre Francisco Martins Dias e os "Traços Históricos e Descriptivos de Bello Horizonte". Revista Eletrônica Cadernos de História, vol. VI, ano 3, nº. 2, dezembro de 2008. Disponível em: < http://www.ichs.ufop.br/cadernosdehistoria>. Acesso em: 12 set. 2014.

SOUZA, Rosa Fátima de. Templos de civilização: a implantação da Escola Primária Graduada no Estado de São Paulo (1890 - 1910). São Paulo: Unesp, 1998.

VINCENT, Guy; LAHIRE, Bernard; THIN, Daniel. Sobre a história e a teoria da forma escolar. Educação em Revista, Belo Horizonte, n33, jun/2001.

\footnotetext{
${ }^{1}$ Doutora em Educação pela Universidade Federal de Minas Gerais. Professora da Faculdade de Educação da Universidade do Estado de Minas Gerais (UEMG), Belo Horizonte, Brasil. E-mail: vlnogueira2010@gmail.com

2 Doutor em Educação pela Universidade de São Paulo (USP). Professor da Faculdade de Educação da Universidade Federal de Minas Gerais (UFMG), Belo Horizonte, Brasil. E-mail: lucianom@ufmg.br

${ }^{3}$ Sobre essa temática, ver, por exemplo: SOUZA (1998); FARIA FILHO (2000); GONÇALVES (2006); ARAUJO (2006).

${ }^{4}$ Escolhido o local em 1893, no ano seguinte iniciaram-se os estudos preliminares, a desapropriação dos terrenos e, por fim, a aprovação da planta da cidade em 1895. Em dezembro de 1897, inaugurou-se a nova capital (BARRETO, 1996).

${ }^{5}$ Ver, por exemplo: Julião (2011, 1996), Costa e Silva (2008); Passos (2009); Arruda (2000), Oliveira (2011), Santos (2011), entre outros.

${ }^{6} \mathrm{~A}$ saída encontrada pelas elites políticas mineiras se desdobrou em duas direções: "a primeira, discriminatória, no sentido de exclusão desses novos agentes do projeto urbano da cidade; a segunda, regulatória, notabilizando-se pela intolerância aos pobres e suas práticas alternativas de sociabilidade". (VERIANO, op. cit. p. 123 apud AMARAL, 2011, p. 5)

${ }^{7}$ Um estudo sobre as primeiras associações da Capital encontra-se em Passos (2014).

8 Jornal porta-voz da Confederação: O LABOR, ano 1, n.1, p. 1, 18 jun.1905.

${ }^{9}$ O LABOR, ano 1, n.1, p. 1, 18 jun.1905.
} 
${ }^{10}$ As primeiras escolas que buscavam corresponder a esses ideais foram implantadas em São Paulo, no ano de 1893. Em Minas Gerais foram as experiências europeias, norte-americanas e também as de São Paulo e Rio de Janeiro que influenciaram na proposição da Reforma de 1906, que criou os grupos escolares. Esse movimento ecoou por todo o país: Rio Grande do Norte (1908), Mato Grosso (1908), Espírito Santo (1908), Paraíba (1911), Santa Catarina (1911), Sergipe (1916), Goiás (1918) A partir dos anos de 1990 diversas investigações tomaram os grupos escolares, entendidos como parte da política pública para a educação republicana, como objeto de investigação, promovendo uma rica e variada produção nessa área (GONÇALVES, 2004; FARIA FILHO, 2000, SOUZA, 2006).

${ }^{11}$ No ano de sua inauguração, em 1897, havia na Capital duas escolas primárias isoladas, uma para o sexo masculino e outra para o sexo feminino, convertidas em escolas urbanas em fevereiro de 1898. Em junho do mesmo ano foram criadas mais duas cadeiras, uma para cada sexo. Em 1900 mais quatro escolas vieram transferidas de Ouro Preto e, em 1903, foram criadas sete escolas coloniais (BARRETO, 1950).

${ }^{12}$ A saber, por meio da Lei n. 439 de 28 de setembro de 1906.

${ }^{13}$ A partir de 1912 os Grupos Escolares deixam de ser referenciados na forma ordinal e passam a ser designados com nomes de personalidades “cujos nomes e feitos queria-se 'imortalizar' na memória da cidade" (FARIA FILHO, 2000, p. 50)

${ }^{14}$ A Confederação já mantinha uma escola noturna desde 1910, destinada aos operários e aos seus filhos. No Regimento Interno da Escola (1912) estabeleceu normas de funcionamento bastante rígidas, organizando o seu ensino dentro dos moldes estabelecidos para as escolas públicas. Em seu art. $1^{\circ}$ definia explicitamente a Escola como um espaço destinado exclusivamente à instrução, proibindo expressamente "aos alunos, toda e qualquer palestra dentro da Escola" (NOGUEIRA, 2009).

${ }^{15}$ Segundo o Regulamento da Instrução Pública, de 1911, a faixa etária para se frequentar as aulas noturnas no estado era a de 16 a 40 anos de idade. MINAS GERAIS. Decreto de n. 3.191 de 9 de junho de 1911. Aprova o regulamento geral da instrução do Estado. Minas Gerais, Belo Horizonte, 09 jun. 1911.

${ }^{16}$ A maior parte da documentação arquivada no prédio onde a escola funcionava foi danificada, após a sua instalação, pelas constantes chuvas e enchentes do Ribeirão Arrudas, localizado nas proximidades da mesma.

${ }^{17}$ Em virtude do reconhecimento da importância para a educação mineira do bacharel Francisco Assis das Chagas Resende - além da Secretaria, ocupou um cargo no Conselho Fiscal da Caixa Escolar Thomaz Brandão, do G. E. Cesário Alvim e foi membro do Conselho Superior de Instrução Pública - logo após o seu falecimento, o Secretário do Interior, Américo Ferreira Lopes, em 1917, empresta nome o seu nome ao Grupo, que passou a se chamar Grupo Escolar Assis das Chagas.

${ }^{18}$ Maria Paula de Almeida, Maria Glória de Lima, Zulmira Maria da Conceição, Maria Joanna, Maria Pereira, Anna Maria Rocha, Maria Itália, Maria Rita Franco, Maria José Pedro, Maria Caridade Moreira, Maria da Conceição, Cacilda Maria de Jesus, Maria Jacinta, Maria da Conceição Freitas, Georgina Maria da Luz, Maria Isabel, Antonietta Maria de Jesus, Maria da Annunciação, Maria Sebastiana e tantas outras. Atas de exames e visitas do Inspetor ao Curso Noturno da Capital. Bello Horizonte, 26 de novembro de 1914. Anna Cintra de Carvalho. Acervo da E. E. Olegário Maciel.

19 Não se pode desconsiderar, entretanto, que as expectativas sociais se diferiam em relação ao que se esperava das mulheres, principalmente quando consideradas as diferenças de classe. Enquanto para as mulheres das classes média e alta o matrimônio e a maternidade representavam a garantia da constituição de uma classe dirigente sólida para as mulheres das classes baixas seria a maneira de se garantir uma força de trabalho adequada e disciplinada. Enquanto aquelas almejavam um casamento que lhes desse segurança e status, as mulheres das classes populares em sua maioria não se casavam e tinham que trabalhar muito. Para as mulheres pobres o modelo idealizado de mulher era praticamente inviável por razões não só econômicas, que iam de encontro às suas necessidades de subsistência, como também por questões ligadas à própria organização familiar que assumia formas diversas, inclusive com inúmeras famílias matrifocais (NOGUEIRA, 2002).

${ }^{20}$ Livro de actas de exames e visitas do Inspector ao Curso Noturno da Capital. Bello Horizonte, 26 de novembro de 1914, 1915. Anna Cintra de Carvalho. Acervo E.E. Olegário Maciel.

Recebido: $\quad$ março-16 Aprovado: setembro-16 